\title{
$\cos 2270-2$
}

Report

to the

Atomic Energy Commission

On the second year's

research.

Energy. Budgets of Animals:

Behavioral and Ecological Implications

Report No. AT $(11-1)-2270-2$

by the

Department of Zoology:

College of Letters and Science

The University of Wisconsin

Madison, Wisconsin 53706

May, 1974

\section{NOTICE}

This report was prepared as an account of work This repor the United States Government. Neither sponsored by the United star any of their employees, nor any of

Commission, hor subcontractors, or their employees,

their contractors, subconsess or implied, or assumes any

makes any warsanty, expsibility for the accuracy, com-

legal liability or respon any information, apparatus,

pleteness or usefulness of as

product or process disclosely owned rights. 


\section{DISCLAIMER}

This report was prepared as an account of work sponsored by an agency of the United States Government. Neither the United States Government nor any agency Thereof, nor any of their employees, makes any warranty, express or implied, or assumes any legal liability or responsibility for the accuracy, completeness, or usefulness of any information, apparatus, product, or process disclosed, or represents that its use would not infringe privately owned rights. Reference herein to any specific commercial product, process, or service by trade name, trademark, manufacturer, or otherwise does not necessarily constitute or imply its endorsement, recommendation, or favoring by the United States Government or any agency thereof. The views and opinions of authors expressed herein do not necessarily state or reflect those of the United States Government or any agency thereof. 


\section{DISCLAIMER}

Portions of this document may be illegible in electronic image products. Images are produced from the best available original document. 


\section{Abstract}

Climatic effects on predator biomass requirements and its implications for prey population dynamics are being explored using heat transfer models of animals and the microclimates they inhabit. Thermal ecology studies of a semi-aquatic endotherm have been shelved pending further dry fur heat transfer studies. Enhancement and reductions of convection of object (model plants) with different projection densities is described.

"This report was prepared as an account of Governmentsponsored work. Neither the United States, nor the. Atomic Energy Commission, nor any person acting on behalf of the Commission:

A. Makes any warranty or representation, expressed or implied, with respect to the accuracy, completeness, or usefulness of the information contained in this report, or that the use of any information, apparatus, method, or process disclosed in this report may not infringe privately owned rights; or

B. Assumes any liabilities with respect to the use of, or for damages resulting from the use of, any information, apparatus, method, or process disclosed in this report.

As used in the above, 'person acting on behalf of the commission' includes any employee or contractor of the Commission, or employee of such contractor, to the extent that such employee or contractor of the Commission, or employee of such contractor prepares, disseminates, or provides access to, any information pursuant to his employment or contract with the Commission, or his employment with such contractor." 
Overview and Detailed Summary of Past Year's Research

The major long term goal of our group is understanding population dynamics from a mechanistic point of view. A subset of this problem is the evaluation of the consequences of climatic change; both natural and manmade, on populations of animals in ecosystems. Over the past five years, we have developed transient evergy balance models for interactions of ectotherms with their physical environment (Beckmen et al, 1973; Porter et ai, 1973; Porter \& Tracy, 1974). We have simultaneously developed a general micrometeorology model for desert regions that allows us to specify micro-climates and therefore, energy fluxes into and out of animals in those micro-climates. To illustrate the principles involved in our proposed research on energy balance modeling of ectotherms and endotherms in decifuous regions, I will briefly describe work we have completed on a. desert lizard and then describe some of the garter snakefrog predator-prey modeling we have done these past two years with AEC support, and then describe some of our recent AEC supported research on convection from objects with different densities of projections (density effects on air flow patterns through bounded "porous" media).

Figure 1 illustrates the flows of energy into and out of both the substrate and the animal on the substrate. 
s.

Energý baliance equations can be developed for both the animal and the substrate as described in Beckman, Mitchell and Porter (1973). The basic equation states that:

$$
E_{\text {in }}+E_{\text {gen }}=E_{\text {out }}+E_{\text {st }}
$$

More explicitly,

$$
\begin{aligned}
E_{i n} & =\text { solar absorbed } \\
& =\text { direct solar \& scattered solar \& reflected solar } \\
& =\alpha_{S} S A_{p}+\alpha_{s} s A_{s}+\alpha_{r} A_{r}(S+s)
\end{aligned}
$$

$E_{\text {gen }}=$ metabolic heat production $=\mathbf{M}$

$$
\begin{aligned}
& \begin{aligned}
E_{\text {out }}= & \text { net thermal radiation exchange with sky \& net th } \\
& \text { exchange with ground + convection + conduction }+ \\
& \text { evaporation } \\
= & \varepsilon \sigma F_{s-s k y} A\left(T_{s}{ }^{4}-T_{s k y}{ }^{4}\right)+\varepsilon \sigma F_{s-g r d} A\left(T_{s}{ }^{4}-T_{\text {grd }}{ }^{4}\right)
\end{aligned} \\
& +h_{c} A\left(T_{s}{ }^{-T_{a i r} \text { local }}\right)+k A_{c}\left(\dot{T}_{s}-T_{\text {deep }}\right)+ \\
& \text { L.E. } h_{D} A\left(\rho_{s}-\rho_{\text {air }}\right)
\end{aligned}
$$

$E_{s t}=$ stored thermal energy $=m c \frac{d T s}{d t}$

I will spare the reader from the many equations involved in both the micro-climate modeling and the animal energy balance modeling. "If more detailed information is desired on the equations involved, the first two papers 
cited on the first page explain them in detail. Evaluation of the parameters in these equations allows us to predict the temperature of an ectothermic animal at any point in time throughout the year. Figure 2 illustrates a desert iguana temperature simulation for a typical 15 th of July in Palm Springs, California. Assuming a desert iguana is standing on the surface throughout the day, the solid line shows the animal's temperature throughout the day. Since the animal has a preferred temperature range between $38^{\circ} \mathrm{C}$ and $43^{\circ} \mathrm{C}$, we expect the animal to be out only during the period of time when he could maintain his body temperature between these limits. Thus, this simulation predicts that an animal that cannot get up above the surface must have a bimodal period of activity for this time of year. We have done extensive tests of the energy balance model predictions in the laboratory, in the Biotron at the University of Wisconsin, and in the Mojave Desert where we have continuously observed these animals for periods up to two weeks in the spring, summer, and fall. For exposed, open burrows on flat surfaces, we can predict emergence times to at least within half an hour and often within fifteen minutes. Times of retreat are often much sooner than we predict. This very well may be due to constraints on the animal in terms of availabie water for evaporation as discussed in Porter, 
Mitchell, Beckman, and DeWitt (ibid.).

Monthly simulations do ne for the entire year are illustrated in figure 3. Here the 15th of July may be compared with figure 2 to illustrate how, starting from midnight on July 15, the constant temperature lines for the animal's body temperature are used to predict emergence, time spent in the open, time spent in the shade, and time spent in the burrow. This kind of a plot also illustrates when the animals should be entering hibernation in the fall and emerging in the spring. Available data in the literature (Norris, 1967; Mayhew, pers. comm.) show that these animals emerge some time in early March and enter hibernation some time in late september or early October. Since these simulations are done using the average Palm Springs temperatures for ten years, we consider this to be a reasonable first approximation to modeling the annual activity patterns of desert iguanas. In Porter et al (ibid.) this modeling is extended to include effects on activity patterns of bushes in the environment, food and water requirements and a single hypothetical predator-prey interaction (fig. 4).

\section{Garter snake - Frog Predator-prey Interactions}

Holling (1966) has done a number of fascinating predatorprey studies. The stimulus from his papers prompted us to investigate potential ramifications of predator-prey 
analyses using activity pattern overlap. We examined garter. snakes (Thamnophis sirtalis) and the leopard frog (Rana pipiens). These animals occur over a wide range of latitudes and since they are near water or in water, they are potentially subject to thermal pollution effects which may alter their activity patterns and affect survival of frog eggs and tadpoles.

The northern location we chose was Pellston, Michigan. Climatological data is available for this area and extensive experiments have been done principally by Dole (1965) on Rana pipiens. Garter snake ecology was also done for this region by Carpenter (1952). We chose as a southern location, Aiken, South Carolina. Again climatological data are available and extensive observations of both garter snakes and frogs have been made there. The capability for applying energy and mass balance equations to determine activity patterns of frogs was developed by Tracy (1972). It was clear based on these frogs' wide temperature tolerance that they would be active at virtually anytime of the year except when the air temperature dips below freezing. The garter snake has much less time for activity because of its minimum activity temperature of $15^{\circ} \mathrm{C}$. An analysis of an energy balance equation on this animal showed us that it was very tightly coupled to soil temperature despite the fact we measured a solar absorptivity of $88 \%$ on our DK-2A spectro- 
reflectometer. Since these snakes typically inhabit moist, tall grassy shady areas, we examined micrometeorological studies of dense vegetative cover by Rose et al, (1971), Byrne and Rose (1972), and Goncz and Rose (1972). Their studies indicate that air temperature profiles down into deep vegetation are essentially equal to air temperatures at $200 \mathrm{~cm}$ above the ground. Since soils are moist where frogs and these snakes occur, we could expect that soil surface temperatures should stay within a few degrees of air temperature. Furthermore, since sunlight would be greatly attenuated passing through dense vegetation cover, there should be little solar intensity driving soil temperatures up. Thus we assumed as a first approximation that ground surface temperatures were the same as air temperature at $200 \mathrm{~cm}$. As we will see below, errors in predicted temperatures of this order of magnitude make little difference in the conclusions.

Figures 5,6 , and 7 show calculations for the activity times of garter snakes in Michigan and South Carolina and an extreme case in South Carolina where an arbitrary $10^{\circ} \mathrm{C}$ increase in air temperature has been added at all times to simulate an extreme situation of thermal pollution. The minimum of $15^{\circ}$ for activity seems to be typical for a variety of species of garter snakes. Carpenter (ibid) found that the mean preferred temperature for Thamnophis sirtalis sirtalis, $\underline{\text { T. }}$ s. sauritus, and $\underline{\mathbf{T}}$. butleri is 
approximately $25.6^{\circ} \mathrm{C}$. He found activity temperatures to lie between $20^{\circ} \mathrm{C}$ and $30^{\circ} \mathrm{C}$. Heckrotte (1961) demonstrated that $\underline{T}$ radix is not active below $15^{\circ} \mathrm{C}$. Stewart (1965) determined that $\underline{\mathrm{T}}$. $\underline{\mathbf{s}}$. concinnus and $\underline{\mathrm{T}}$. ordinoides prefer temperatures between 25 and $30^{\circ} \mathrm{C}$, have a minimum preferred temperature of $17^{\circ} \mathrm{C}$ and tolerate a maximum of $35^{\circ} \mathrm{C}$. Kitchell (1969) demonstrated the $\underline{T}$. sirtalis has a minimum preferred temperature of $16^{\circ} \mathrm{C}$ when shedding and has higher minimums for other activities. We have not yet adjusted.the results for acclimation in this first simulation, though Jacobson and Whitford (1970) have shown acclimation effects on the physiology of $\underline{T}$. proximus.

Figures 5,6 and 7 were computed using the 10 year average temperatures between 1960 and $1969^{\prime}$ for each region. The predictions suggest that garter snakes should be active about 20 weeks in Michigan, about 40 weeks in Aiken, Sputh Carolina, and should be active year round if Aiken should have $10^{\circ} \mathrm{C}$ thermal pollution. Field observations near pellston by Dan Ritschoff and near Aiken by Whit Gibbons (pers. comm.) indicate that the length of seasonal activity in these regions is very close to what we have predicted. since the climate fluctuates from day to day, particularly in northern regions, it would seem essential to examine the day to day sequence of temperatures particularly in the spring and fall when some days would not reach $15^{\circ} \mathrm{C}$ and therefore prevent garter snakes from actively hunting or digesting (Skoczylas, 1870). Figure 8 is Weather-Bureau 
data taken for April and May in Pellston, Michigan in the year 1960. This particular year had monthly averages that were nearly identical to the 10 year average for that location. The first day that exceeded $15^{\circ} \mathrm{C}$ maximum temperature was about the 15th of April. As late as May 23, there was a day whose maximum temperature did not exceed $15^{\circ} \mathrm{C}$. Since garter snakes can apparently only hunt at body temperatures above $15^{\circ} \mathrm{C}$, it seemed that the frequency and spacing of days exceeding $15^{\circ}$ might be of vital importance to an animal freshly out of hibernation that is trying to obtain enough food to survive. This concept is illustrated in Figure 9 where the first part of May in 1960 is examined in detail. The first two days the animal could not exceed $15^{\circ}$ at any time and it is not until approximately 1000 hours that the animal could begin to hunt. If prey is captured at 1600 hours on May 4 th, only about 3 hours would be available for digestion since the snake body temperature drops below $15^{\circ} \mathrm{C}$ at about that time. Since the following day is cooler, only about 3 hours are available during that day to carry on digestion. It is apparent that for the animal to survive, the digestion rate must berapid enough to permit the snake to abtain sufficient energy to make up for times when it is too cold to hunt or digest. Figures 10 and 11 show the potential calọies available from digestion if we assume the $50 \mathrm{gm}$ snake has a full stomach and is exposed to average climatic conditions for Michigan and South Carolina. Also 
shown near the bottom of the graph is the metabolic requirement for the animal for each day of the year. Skozcylas' careful work using $\mathrm{x}$-rays and dissections demonstrated that digestion was completely arrested at $5^{\circ} \mathrm{C}$, at $15^{\circ} \mathrm{C}$ was very slow or intermittant and was most rapid at about $25^{\circ} \mathrm{C}$. Since there is no data in the literature on digestion as a function of temperature for the garter snake, we have used Skozcylas' 1970 data on Natrix natrix for our calculations of digestion for the garter snake. Unfortunatly, he made no determinations of digestion at $30^{\circ} \mathrm{C}$ and the digestion rates he observed at $35^{\circ} \mathrm{C}$ were lower than rates at $25^{\circ} \mathrm{C}$. We therfore assumed a $Q_{10}$ increase of 2 for digestion rates between $25^{\circ} \mathrm{C}$ and $30^{\circ} \mathrm{C}$. We assumed a logarithmic decrease from a projected $30^{\circ} \mathrm{C}$ value to the measured $35^{\circ} \mathrm{C}$ value, and we assumed that no digestion occurs above $40^{\circ} \mathrm{C}$. Thus if garter snake digestion rates are similar to those of Natrix, then the rate of digestion is orders of magnitude higher than the rate of metabolism for any given day. Thus, in modeling the garter snake, the daily sequence of temperature is not significant and averages are sufficient.

Integrated metabolism was computed (Porter and Tracy, 1974) using metabolic rates typical of snakes based on work by Jacobson and Whitford (ibid), Dmi'el (1967), Dmi'el and Borut (1972), Dimi'el (1972) and others.

Integration of the area under the metabolism curves for Pellston, Michigan and Aiken, South Carolina yield the 
total energy requirement for a $50 \mathrm{gm}$ garter snake for an entire year and are shown in Table 1. A $50 \mathrm{gm}$ garter snake would need approximately 79,500 calories to maintain itself for an entire year. The total caloric requirement needed allows one to estimate the biomass required for the sanke to maintain itself for a year. We assumed a low digestive efficiency of 368, inferring this from data of Brown (1958). The reader can easily revise our calculations to reflect other digestive efficiencies. If our assumptions are used, less than six $40 \mathrm{gm}$ frogs are needed for maintenance requirements for an entire year. The results of Myer and Kowell (19.71) on king snakes suggest that their digestive efficiencies are typically higher than those we are assuming. Furthermore, work by Vinegar, Hutchinson and Dowling (1970) on pythons shows digestive efficiencies above 50\%. Thus our, biomass estimates for garter snake maintenance are probably high. Table 1 show's that if the biomass required for reproduction is considered, an additional 136 grams of biomass is needed. This assumes a maximum production of young of 34 individuals annually (Hoffman, 1970). Assumptions as to assimilation efficiency and pereent water content of snake biomass are indicated on the table. The number of frogs needed to meet these biomass requirements varies from slightly more than three 3rd year frogs to 136 newly emerged frogs. It seems clear that the simplest feeding strategy for snakes would be to attempt to obtain the largest frogs possible and thereby reduce the amount of time needed 
for hunting. The consequences for the frog population might: be very different depending upon snake feeding strategies.

A final consideration in this estimation of total biomass requirements for garter snakes would be an increase in size of the animal. We assume a doubling of weight due to growth and a $25 \%$ assimilation efficiency (Brown, (ibid)). We find an additional 200 grams biomass needed. This is nearly the same amount as required for annual maintenance in Michigan. Total biomass requirements for maintenance, reproduction, and growth for $50 \mathrm{gm}$ garter snakes are about $550 \mathrm{gm}$ wet weight of biomass for Pellston, Michigan area and approximately $700 \mathrm{gms}$ for Aiken, South Carolina. If maintenance only is considered, only half of the above biomass requirements are needed to support an animal for an entire year.: Thus, an animal in the Pellston, Michigan area that is eating only 3rd year frogs could survive on six frogs per year. With 20 weeks of activity time available, that would be an average of one frog a month to less than one frog a week. Similar feeding intervals would be expected for Aiken, South Carolina where there are an average of 40 weeks of available activity time. Our calculations also suggest that a $10^{\circ}$ increase in year 'round temperatures in Aiken would double the maintenance requirements of garter snakes but only increase the overall annual requirement by about 508. This assumes no significant temperature effect on the biomass requirements of developing embryos. 
Since an individual snake would seem to consume rela:tively few frogs, we examined an active endotherm predator to compare its biomass requirements with those of the ectothermic garter snake. We chose mink to make some preliminary estimates of their biomass requirements. As table 1 indicates, a mink's daily requirement for maintenance is approximately the same as the annual maintenance requirement for a $50 \mathrm{gm}$ garter snake. Oñan equivalent weight basis, 50 gm of mink requires approximately 26 time more prey biomass for maintenance than a $50 \mathrm{gm}$ garter snake. All data used in the calculations were taken from Farrell and Wood (1968). We have not made any estimates of biomass requirements for reproduction and growth in mink, but the mass required must be significant. Since reproduction in both snake and mink takes place over a relatively narrow time period of about 2 months, it must be during reproduction when hunting efficiency must be greatest to obtain several times the biomass needed for maintenance alone. Failure to obtain sufficient biomass for production of young will result in fewer offspring. Thus "hunting efficiency" would not only depend on hunger level, but also on the reproductive or endocrine state of the female. The short time interval for reproduction each year may well be the crucial period of time determining population size the succeeding year. These simple predator-prey analyses have: several implications. First, neglecting reproduction and growth, a 
limiting cáse of biomass relationships between ectothermic predators and their prey could be a ratio of 1:4 rather than the usual $1: 10$ ratio usually assumed. Obviously such a low ratio could not long persist since it precludes predator reproduction. However, it is likely that a population of ectothermic predators could survive for at least a year without reproducing. A second implication is that endotherm biomass densitites must be very much less than ectotherm predator biomass densities because of the more rapid metabolic rate of endotherms. Even though on a per gram basis endotherm biomass requirements are 26 times those of an ectotherm on a per gram basis, endotherms frequently outweigh ectothermic predators. Thus on an individual whole organism basis, vertebrate ectotherm-endotherm predator ratios may approach 400 to 1 .

Finally, it would seem that if thermal pollution were to increase average temperatures by $10^{\circ} \mathrm{C}$, we could expect a doubling of biomass maintenance requirements by ectothermic predators. Endothermic predators may have to shift activity patterns to cooler times of day.

Recently our computer simulations have explored the consequences for a frog population of garter snakes concentrating their predation on various age classes of frogs, e.g. sexually mature adults vs immature juveniles. We. hoped to evaluate the effect of size selection of prey (frogs) on their population stability. At garter snake 
and frog densities that are commonly observed in the field, any snake feeding strategy seems suitable, since there is so little impact on the frog population. An endothermic predator such as a mink, however, is capable of having a large impact if the animal can find enough frogs in a short enough time period to satisfy its needs. From extensive studies on mink predation (mostly scat analysis), in Sweden and Norway, it has been found that wild mink shift their food depending on local abundance. For example, in the spring of the year, when birds are nesting, most of their food is bird eggs (and adults when they aan catch them). In early. summer they switch to crayfish which are abundant. In early fall, they switch to frogs and when winter approaches they switch to mice and other small mammals. The criteria for these switches is unknown. Also unknown is the role of climatic influence on their preferences, e.g. the energy the animal is willing to expend to obtain a food of a given type. The role of environmentally mediated activity times for both predator and prey types is also unknown. Experiments to try to resolve some of these questions, which relate to thermal modification of the environment, are described in the proposed technical program accompanying this report. We have chosen this approach rather than the field study proposed last year for many reasons. First, computer simulations, the literature, and discussions with people around the country doing field studies on frogs, snakes and endo- 
therms' have demonstrated that to keep track of the number of variables needed to do a first rate job, we would need a substantial increase in funding, which was not possible. Second, the local site we would like to use if funding does become available is not completely guaranteed as to its long term integrity yet, though it looks more certain all the time. Third, the special strengths of our group Iie in the development and short term testing of animal-environment interactions that allow a broad range of predictions without extensive field observations. Our problem is now to find a first rate field site where there is already extensive research being done by competent field people and collaborate with them. We have been exploring two such sites, one in Michigan and another in Alberta, Canada and have had excellent cooperation at both. No final decision has been reached yet on which or both sites will be used to validate model predictions.

In summary, energy balance equations for microclimates and animals can be used to predict activity times, food requirements, and potential predator-prey interactions. Preliminary analyses of a simple predator-prey system has raised many more questions than it has answered. The model has pointed to a lack of vital information in the literature on'digestive efficiences, growth rates in the field, biomass requirements for reproduction, and biomass requirements for early growth to maturity. Physiological measurements on a 
variety of active endotherm predators are also absent from the iiterature. Also, information on number of young produced as a function of food available to the mother of virtually any wild mammal as lacking. Such data is needed if we are to develop mechanistic models for multispecies predator-prey interactions in biomes.

\section{Muskrat Energy Exchange}

The proposed study on heat transfer through muskrat fur and muskrat ecology has been set aside for at least two years and possibly more. We need more fundamental data on heat transfer of dry fur before we can tackle the wet fur problem. our engineering colleagues who are jointly funded with us on another grant have made very good progress in unraveling the problem but there is still much to do. Muskrats seem so labile in their food habits and make up such a small component of any predators' diet, that it seems they will be nearly unaffected by any change in the physical environment short of raising the water temperature to $40^{\circ} \mathrm{C}$ year 'round. Mr. Muth who is supported on this grant has shifted to an entirely different project as described in the technical proposal. 
Basic Problems In Air Flow Through Bounded Semi-porous Media

Although it was not in the proposal last year, we have been doing some fundamental research on flow through bounded semi-porous media. This research was initiated principally due to discussions with Bill Osburn. We have been interested in this problem for sometime because it is so fundamental to heat transfer problems in fur, grass, bushes and other kinds of vegetation. It has important implications for particle fallout on the lee side of vegetation. Finally many animals utilize the convective environments of vegetation to either enhance or diminish their convective heat exchange. At present, there is no way of even estimating this effect for an animal in or behind vegetation.

We chose to start with as simple a model as possible and gradually add complexity. That initial model was a "cactus". The hypothesis was this: Projections on a surface at very low densities induce turbulence and greater convection and average wind speeds. As the density of projections increases, eventually they will become so thick that they will begin to insulate the surface and slow down air movement therby decreasing convective effects. Tregear's paper (1965) has some hint of this for animal fur, but it was never followed up. The plant literature has several papers speculating on the function of spines. Heat transfer texts (Kays and London, 1964) discuss packing densities of heat exchange 
elements, but all the flow is forced through the elements. We are exploring the critical densities at which wind penetration patterns shift and how much they shift.

A difficult problem was sorting out convective losses of the spines from the convective losses of the body of the "cactus". We needed to know the effective wind as the body surface "sees" it. We resolved the problem of casting a' cylindrical plaster body and mating identical cylindrical sections of solid wax on either end to eliminate end effects. Toothpicks were used as "spines" (Fig.1). A technique had to be devised to wet the plaster body without wetting the plastic toothpicks. By measuring the mass transfer rate of water from the body of the cactus, we could determine a mass transfer coefficient $\left(h_{D}\right)$ and hence a heat transfer coef-. ficient $\left(h_{C}\right)$ by the following equations.

$$
\begin{aligned}
& h_{w}=\frac{\dot{A} h_{D}\left(\rho \operatorname{surf}^{-\rho} \text { air }\right)}{h_{C}=} \frac{h_{D} C_{p}{ }^{\rho}}{\left(\frac{P r}{S C}\right)^{2 / 3}}
\end{aligned}
$$

where

$$
\begin{aligned}
\mathrm{w}_{\mathrm{w}} & =\text { mass flow of water } \\
\mathrm{A} & =\text { area of mass transfer } \\
\rho_{\text {surf }} & =\text { water vapor density at surface } \\
\rho_{\text {air }} & =\text { water vapor density of the air } \\
\mathrm{h}_{\mathrm{D}} & =\text { mass transfer coefficient } \\
\mathrm{C}_{\mathrm{p}} & =\text { specific heat of air } \\
\rho & =\text { density of air } \\
\mathrm{Pr} & =\text { Prandtl Number } \\
\mathrm{Sc} & =\text { Schmidt Number }
\end{aligned}
$$


The heat transfer coefficient is related to velocity by non-dimensional parameters, the Nusselt Number (Nu) and the Reynolds Number (Re):

$$
\mathrm{Nu}=\frac{\mathrm{h}_{\mathrm{c}}^{\mathrm{L}}}{\mathrm{K}} \quad \therefore \mathrm{Re}=\frac{\rho \mathrm{VL}}{\mu}
$$

where

$$
\begin{aligned}
& \mathbf{L}=\text { characteristic dimension (diameter) } \\
& \mathrm{K}=\text { conductivity of the fluid (air) } \\
& \mu=\text { dynamic viscosity of the fluid (air) } \\
& V=\text { velocity of the fluid (air) }
\end{aligned}
$$

When plotted against each other on a log-log scale the Nu-Re relationship allows one to scale size and wind speed up or down and thereby predict other situations.

Figure, shows the results of some of the early experiments. We now have higher spine densities that show a drop in "cactus" convection heat transfer below that of a bare cylinder. Many technical difficulties with materials and techniques have slowed the work, but we expect to complete the first phase of this work well before summer is over:

We are now initiating the second phase of the study, i.e. the development of arrays of elements of different densities. Because of Reynolds Number scaling and the requisite very small element diameters, we are using different techniques for some of the arrays. The arrays represent model trees and bushes of different densities as the wind "sees" them as well as a blow up of the "cactus" surface 
and some types of fur and grassy vegetation (depending on the scaling). 


\section{Bibliography}

Beckman, W. A., J. W. Mitcheli and W. P. Porter. 1973. Thermal Model for Prediction of a Desert Iguana's Daily and Seasonal Behavior. Trans. ASME. J. Heat Transfer May: 257-262.

Brown, E. E., 1958. Feeding Habits of the Northern water snake, Natrix sipedon sipedon linneaus. Zoologica, 43 (2): 55-71.

Byrne, G.F., and C.W. Rose. 1972. On the Determination of Vertical Fluxes in Field Crop Studies. Agric. Meteorol., 10:13-17.

Carpenter, Charles C., 1952. Growth and Maturity of the Three Species of Thamnophis in Michigan. Copeia 1952.(4): 237-243.

Dmi'el, Razi; 19.67. Studies on Reproduction, Growth, and Feeding in the Snake Spalerosophis cliffordi (Colubridae). Copeia,

1967 (2): $332-346$.

Dmi'el, Razi, 1972. Relation of Metabolism to Body Weight in Snakes. Copeia, 1972, (1): 179-181.

Dmi'el, Raxi, and.A. Borut, 1972. Thermal Behavior, Heat Exchange and Metabolism. in the Desert Snake Sphalerosophis cliffordi. Physiol. Zool. 45 (1): 78-94.

Dole, J. W., 1965. Summer Movements of Adult Leopard Frogs, Rana pipiens Schreber, in Northern Michigan Ecology. 46: 236-255.

Farrell, D. J., and A.J. Wood, 1968. The Nutrition of the Female Mink Mustela vison. II: The Energy Requirement for Maintenance. Canadian Journal of Zoology, 46: 47-51.

Goncz, J.. H. and C.W. Rose, 1972. Energy Exchange Within the Crop of Townsville Stylo, Stylosanthes humilis H.B.K. Agric. Meteorol., 9: 405-419.

Heckrotte, Carlton, 1961. The Effect of the Environmental Factors in the Locomotory Activity of the Plains Garter Snake Thamnophis radix radix. Animal Behavior, $\mathrm{X}$, 3-4: 193-207.

Hoffman, Loren H., 1970. Observations of Gestation in the Garter Snake, Thamnophis sirtalis sirtalis. Copeia, 1970, (4): 779-780.

Holling, C. S., 1966. The Strategy of Building Models of Complex Ecological Systems in Systems Analysis in Ecology, e.d. K. Watt, Acad. Press.

Jacobson, Elliot R. and Walter G. Whitford. 1970. The Effect of Acclimation of Physiological Responses to Temperature in the Snakes, Thamnophis proximus and Natrix rhombifera. Comp. Biochem. Physiol., 1970, Vol. 35, pp.439-449. Pergamon Press. Great Britain. 
Kays, W. M. and A. I. London, 1964. Compact Heat Exchangers. Second ed. McGraw-Hill. New York, pp. 272.

Kitchell, James F., 1969. Thermophilic and Thermophobic Responses of Snakes in a Thermal Gradient. Copeia 69(1): 189-191.

Myer, James S. and Arthur P. Kowell, 1971. Eating Patterns and Body Weight Change of Snakes When Eating and Whan Food Deprived. Physiology and Behavior. Vol. 6, pp. 71-74. Pergamon Press. Great Britain.

Norris, K. S. 1967. Color Adaptation in Desert Reptiles and Its Thermal Relationships. Symposium on Lizard Ecology. 'W. Milstead, ed. 162-229.

Porter, W. P., J. W. Mitchell, W. A. Beckman, and C. B. DeWitt. 1973. Behavioral Implications of Mechanistic Ecology (Thermal and Behavioral Modeling of Desert Ectotherms and their Microenvironment). Oecologia 13: 1-54.

Porter, W. P. and C. R. Tracy, 1974. Modeling the Effect of Temperature Changes on the Ecology of Rana pipiens and Thamnophis

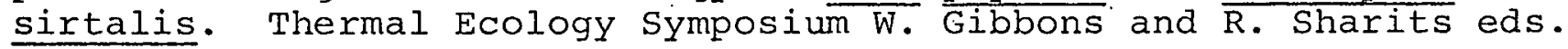

Roberts, M. F., 1972. Models for Heat Transfer and Thermal Regulation of a Hairless Gerbil. Ph.D. Thesis, U. Wis., Madison.

Rose, C. Q. , J. E. Begg, G. F. Byrne, J. H. Goncz and B. W. R. Torssell. 1971. Energy Exchanges Between a Pasture and the Atmosphere Under Steady and Non-Steady-State Conditions. Agric. Meteorol., 9: 385-403.

Skoczylas, Rafal. 1970. Influence of Temperature on Gastric Digestion in the Grass Snake, Natrix natrix 1. Comp. Biochem. Physiol., Vol. 33, pp. 793-804. Pergamon Press. Great Britain.

Stewart, Glenn R. 1965. Thermal Ecology of the Garter Snakes Thamnophis sirtalis concinnus (Hallowell) and Thamnophis ordinoides (Baird and Girard). Herpetologica, Vol. 21, No. 2, pp. 81-103.

Tracy, C.R., 1972. A Model of the Water and Energy Dynamic Interrelationships Between an Amphibian and Its Environment. Ph.D. Thesis, U. Wis., Madison.

Tregear, R. T., 1965. Hair Density, ir nd speed and Heat Loss in Mammals. J. Appl. Physiol., 20 (4): 796-801.

Vinegar, Allen, V. Hutchinson, and G. Dowling, 1970. Metabolism, Energetics, and Thermoregulation During Brooding of snakes of the Genus Python (Reptilia, Boidae). Zoologica (55): 19-48. 


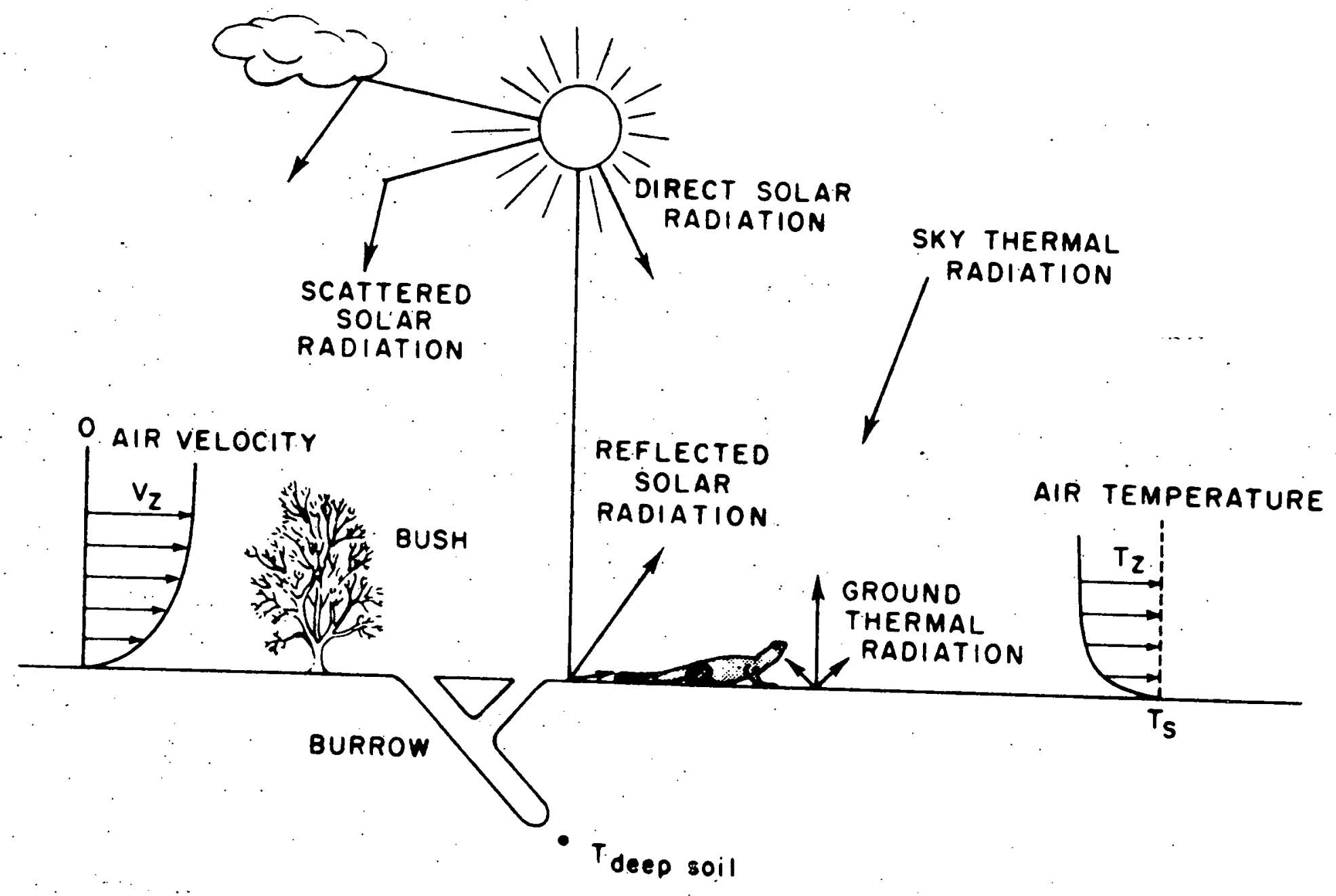

Fig. ( $2^{*}$ Energy flow diagram of the desert environment. 


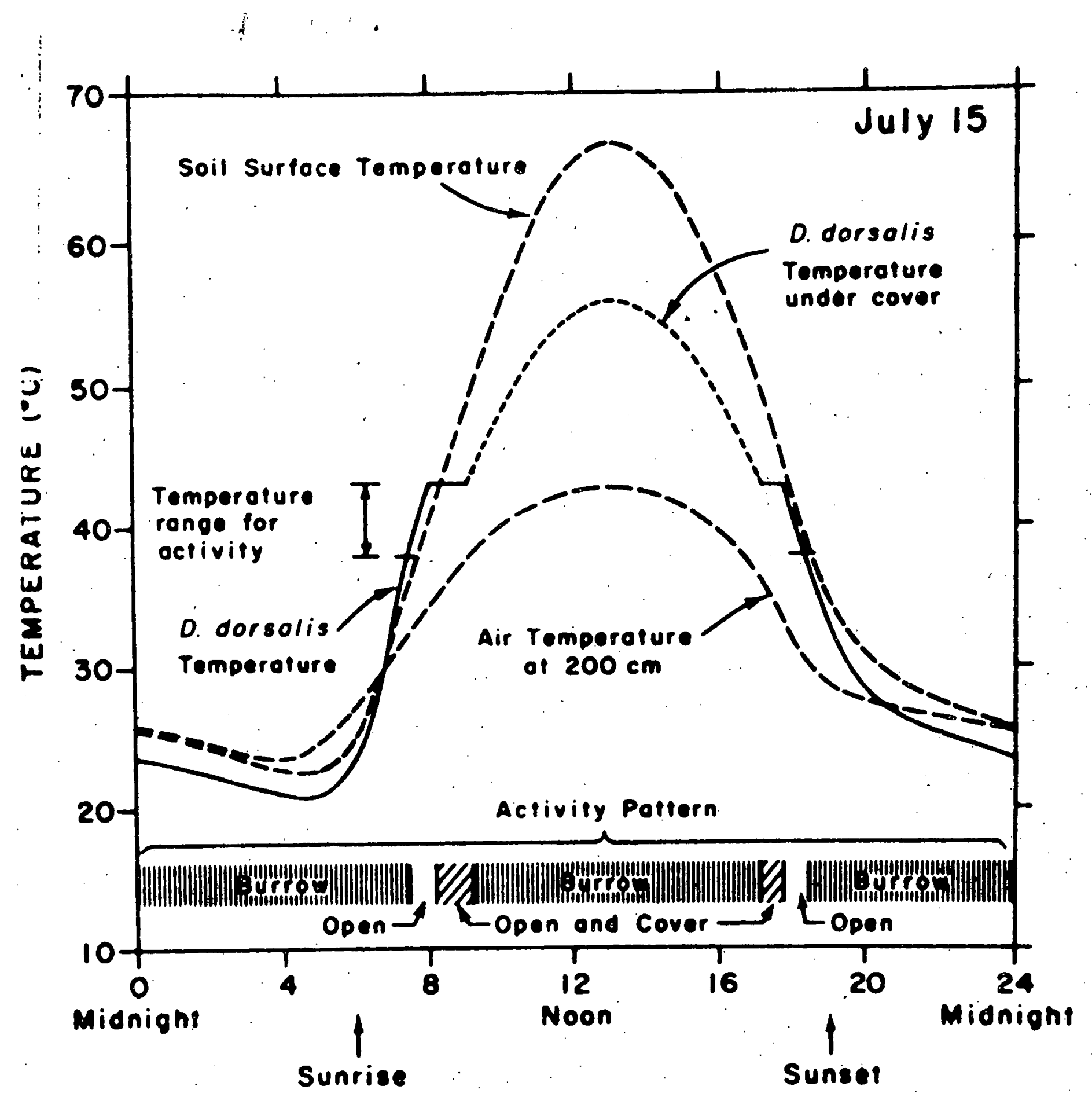

TIME OF DAY (HR)

Fig. 3. Predicted environmental and desert iguana temperatures for Palm Springs, California (July 15) 


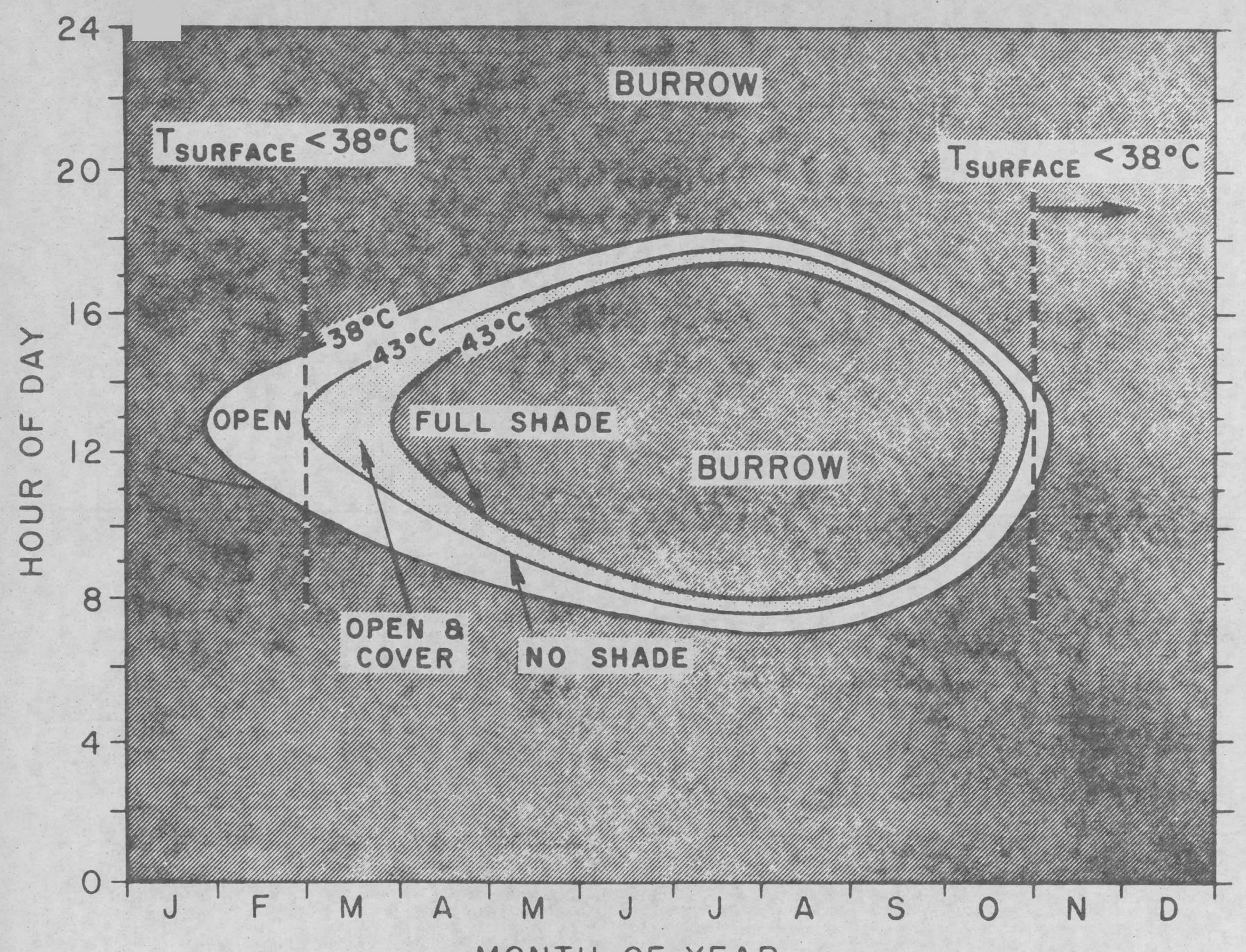

MONTH OF YEAR

Fig. Predicted seasonal behavioral pattern for the desert

iguana at Palm Springs 


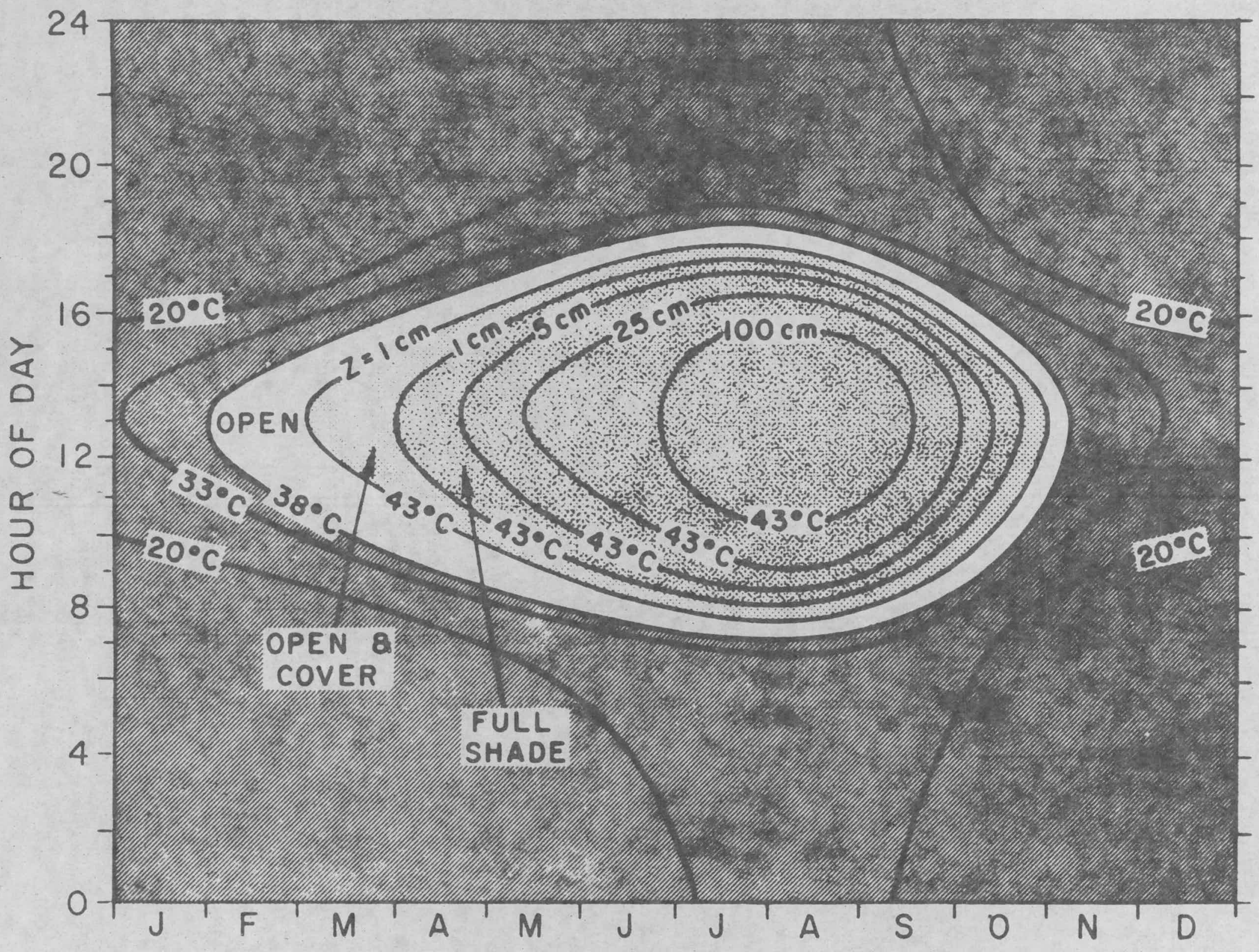

MONTH OF YEAR

Fig. $\$$ Predicted seasonal behavioral pattern for the desert iguana for a wider variety of possible body temperatures and heights $(z)$ above the ground 


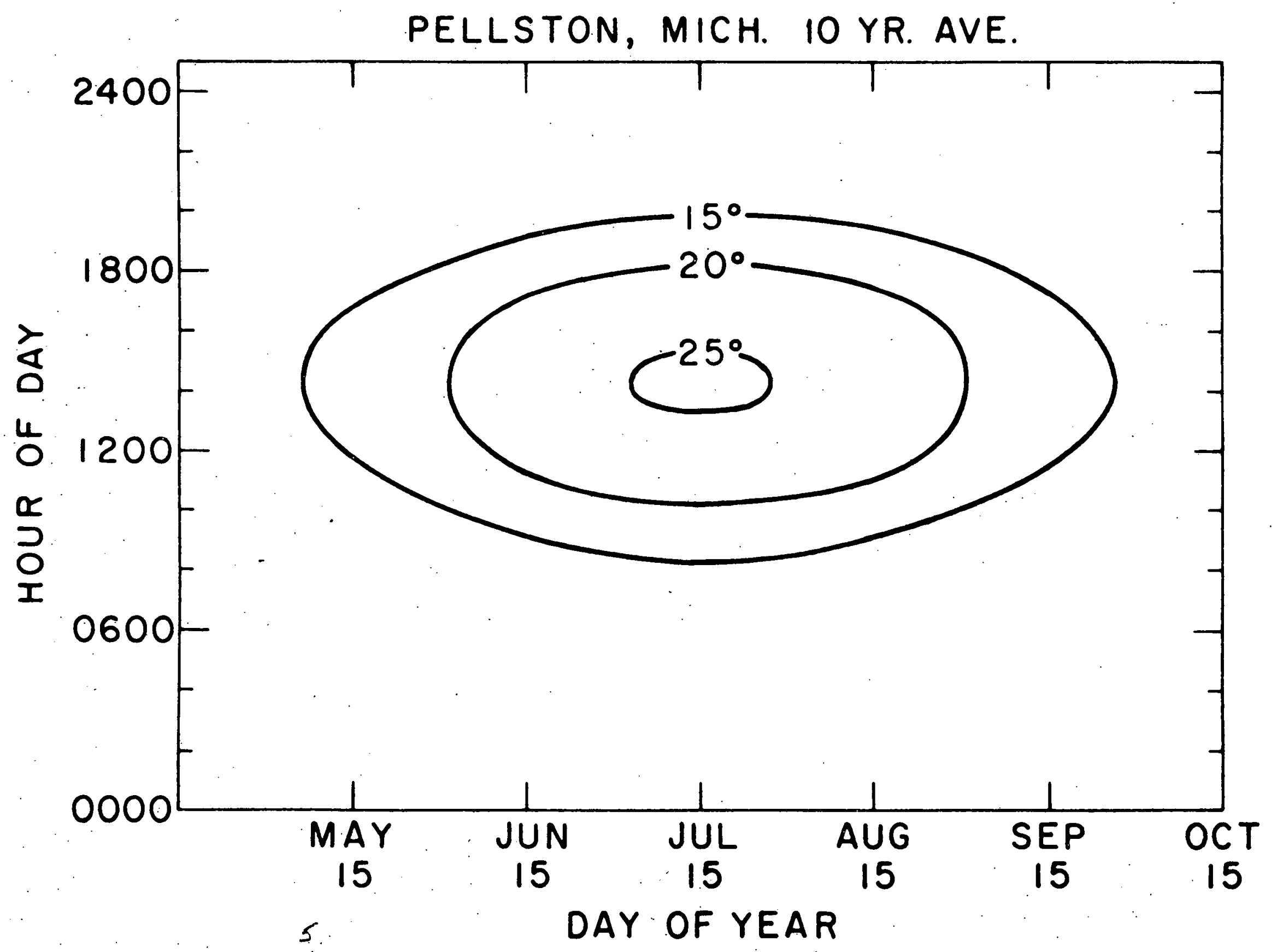

Fig. Y. Predicted seasonal behavioral pattern for garter snakes near Pellston, Michigan 
AIKEN, S.C. 10 YR. AVE.

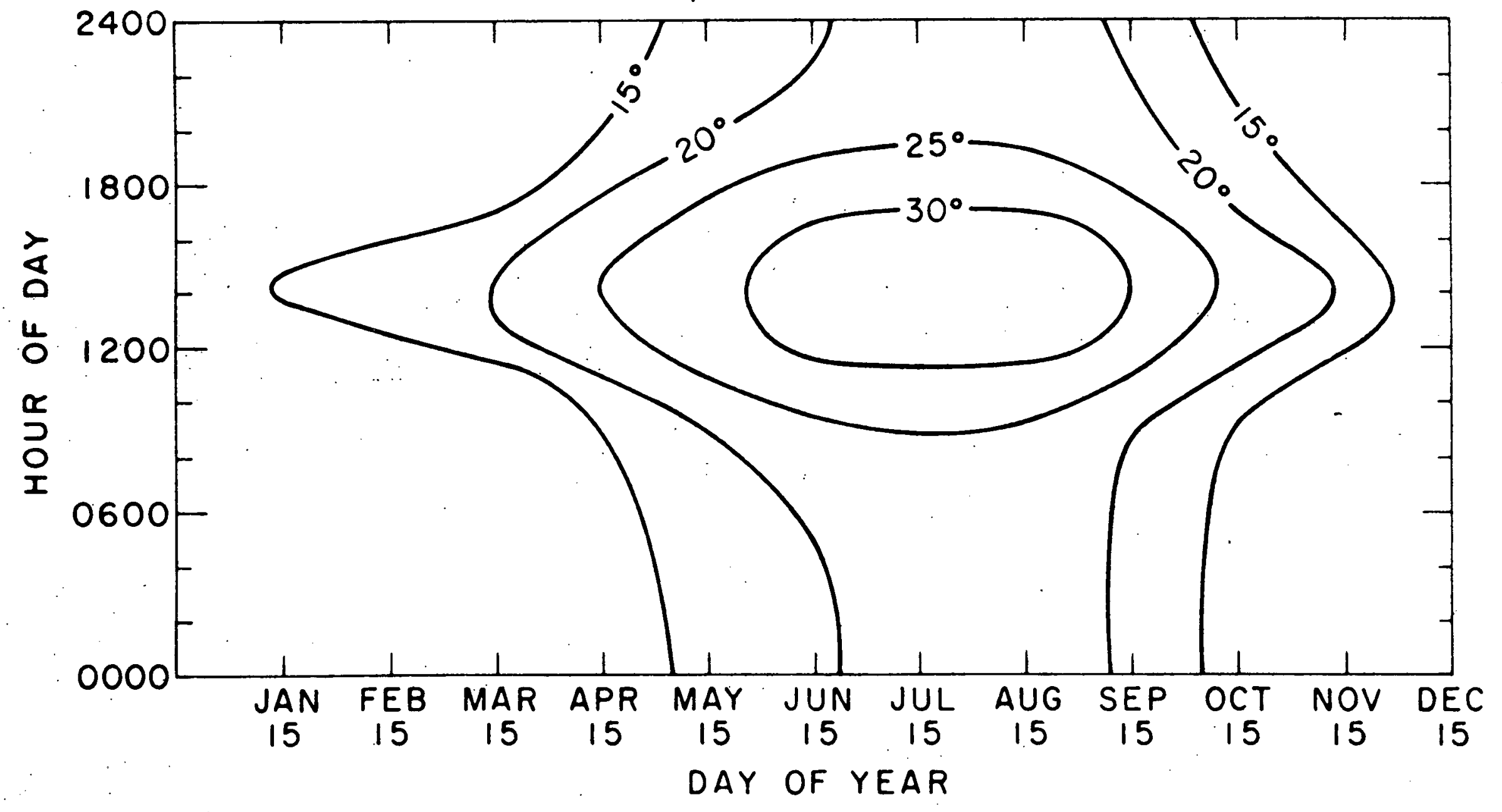

Fig. \$ Predicted seasonal behavioral pattern for garter snakes 


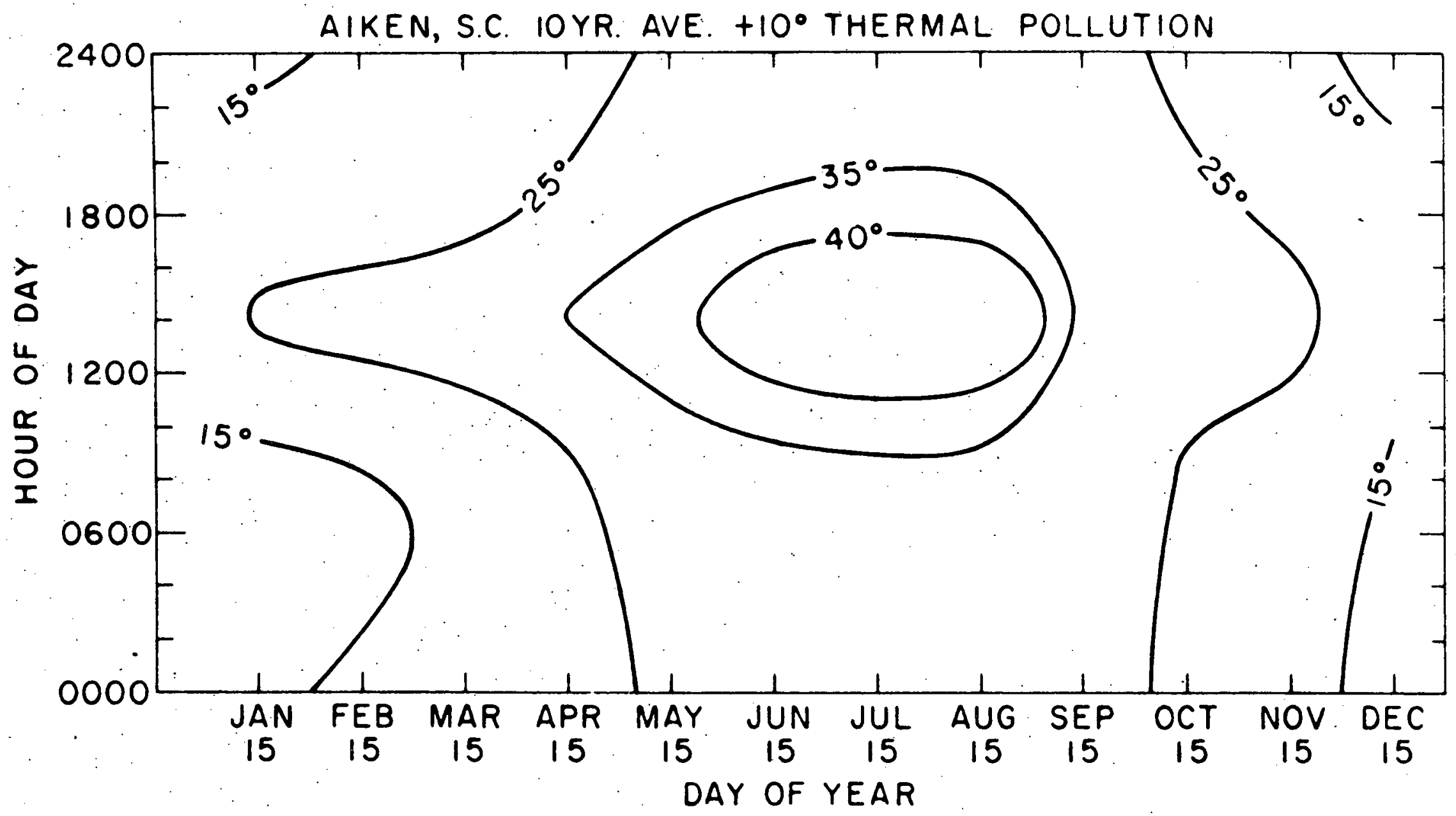

$$
\begin{aligned}
& \text { Fig. Predicted seasonal behavioral pattern for garter snakes } \\
& \text { near Aiken if all air temperatures were } 10^{\circ} \mathrm{C} \text { higher due } \\
& \text { to thermal pollution }
\end{aligned}
$$




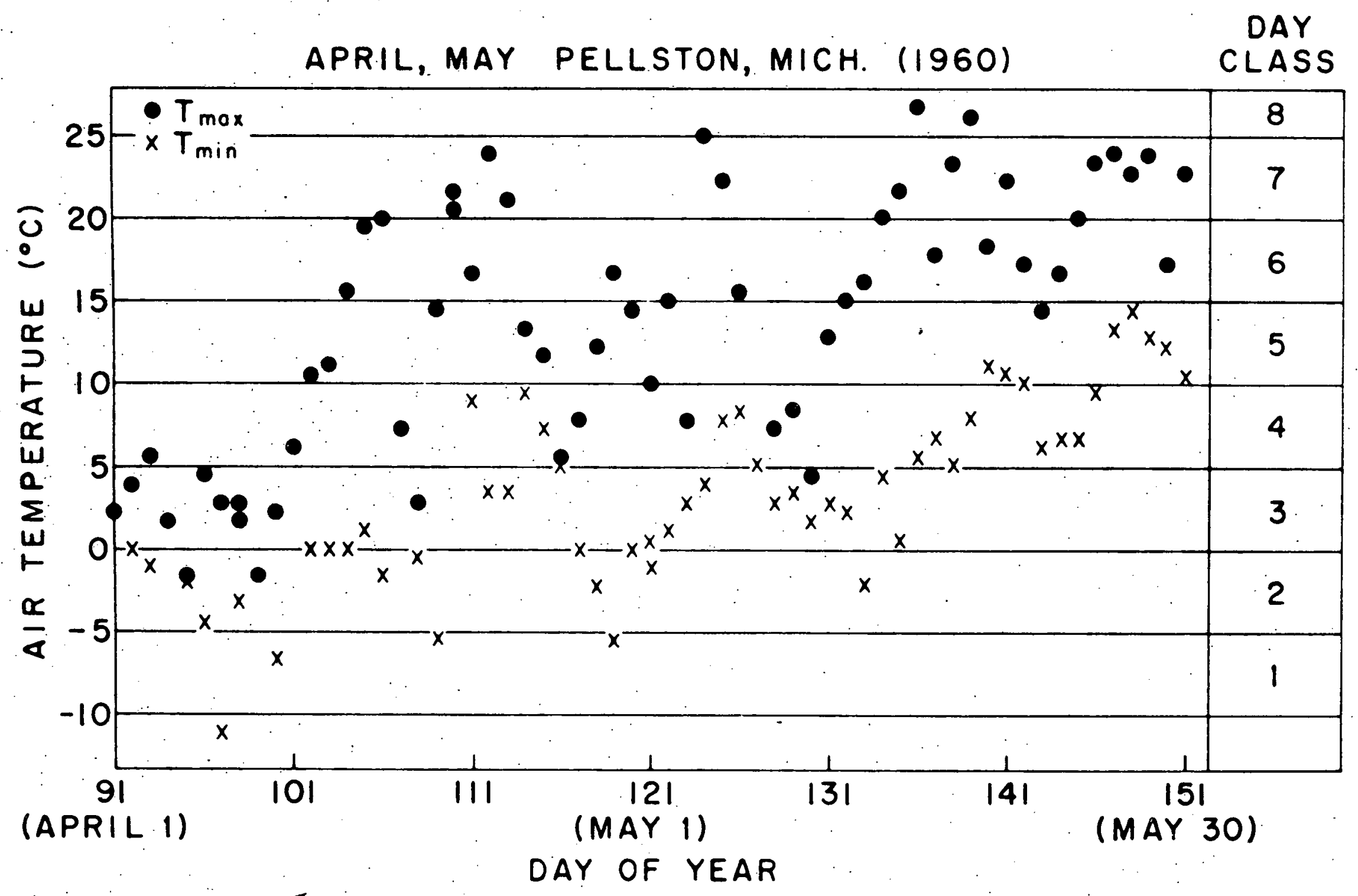

8

Fig. 16 Daily air temperature data from Pellston, Michigan in 1960 


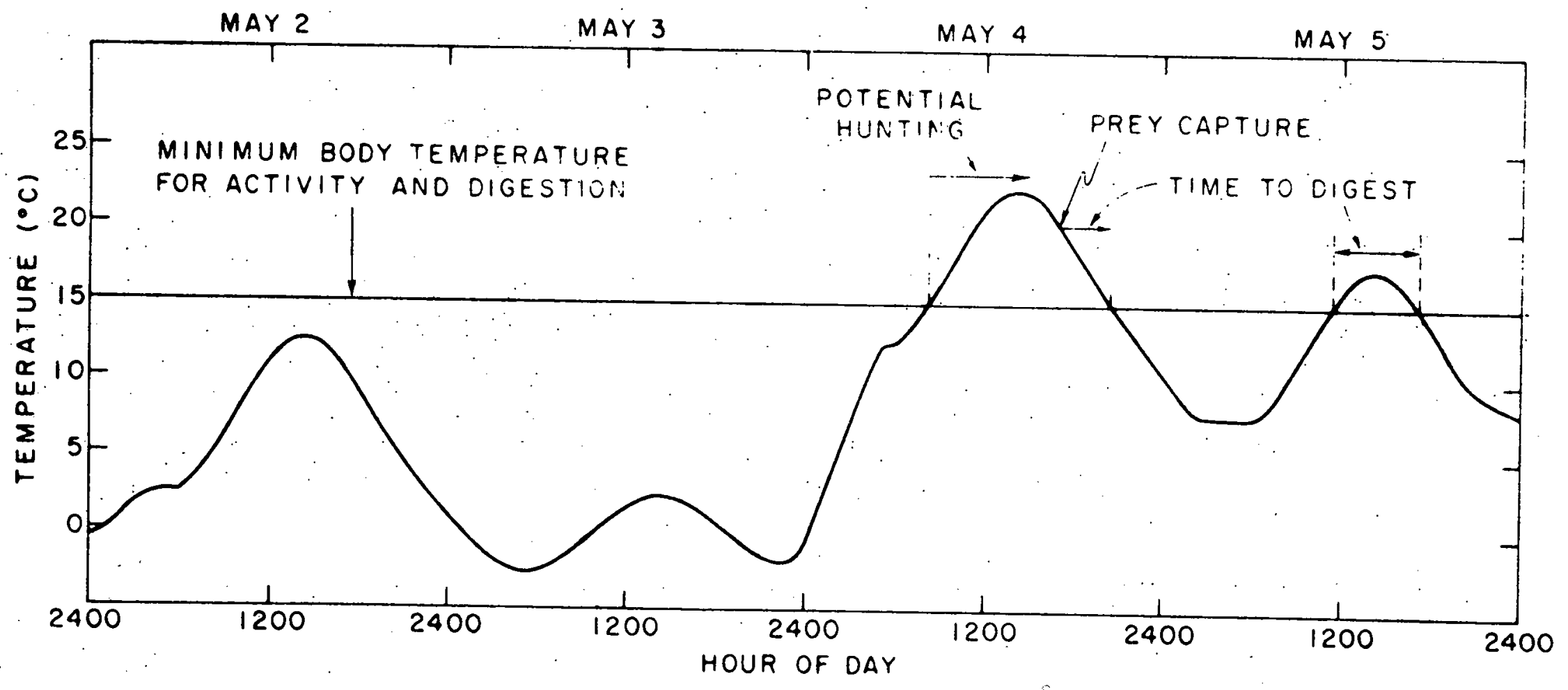

9

Fig. H Limits to hunting and digesting by garter snakes for a short sequence of days in 1960 near Pellston, Michigan 


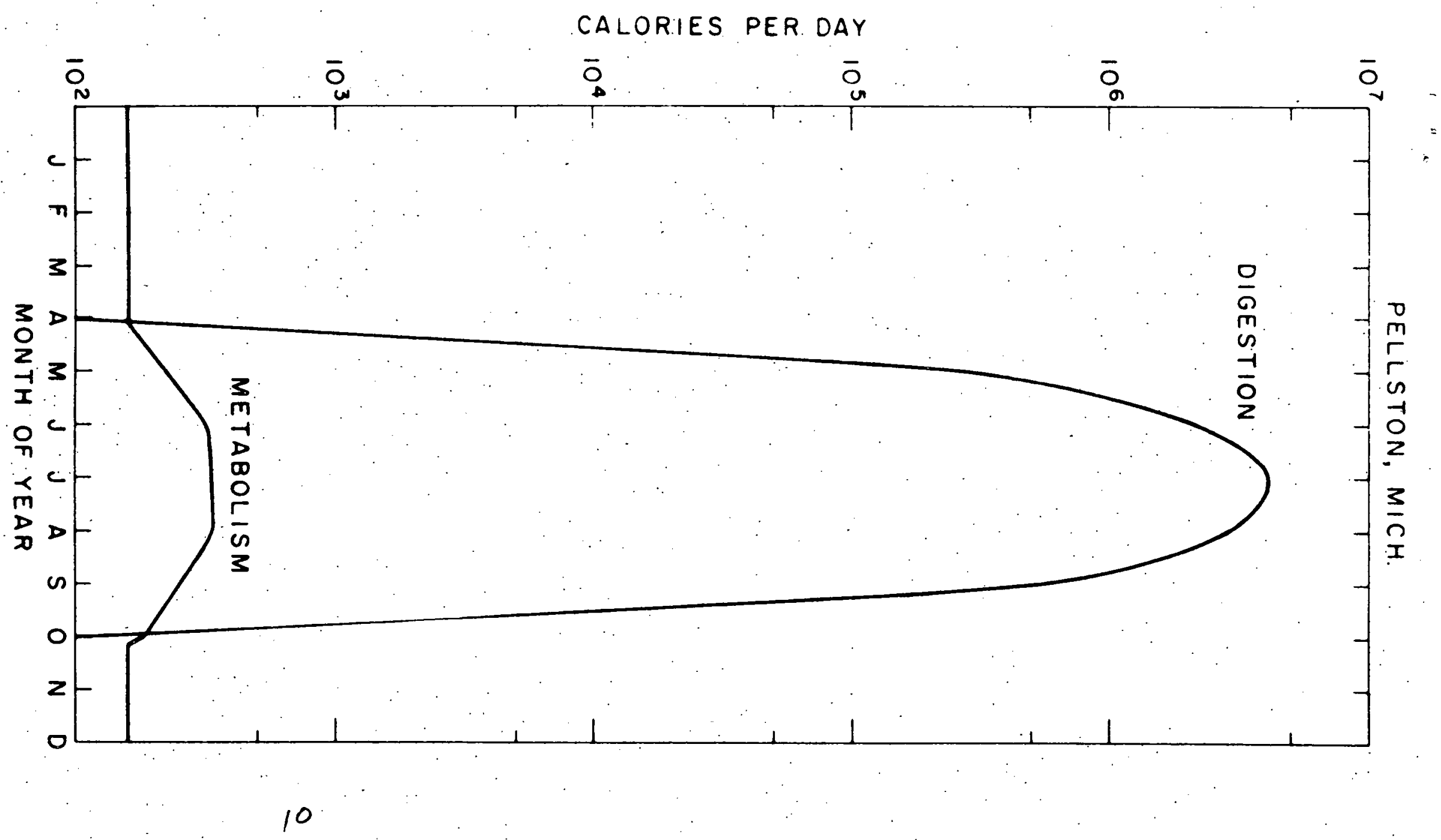

Fig. IX Daily resting metabolism and potential daily maximum digestion using 10 year average days for Pellston, Michigan 


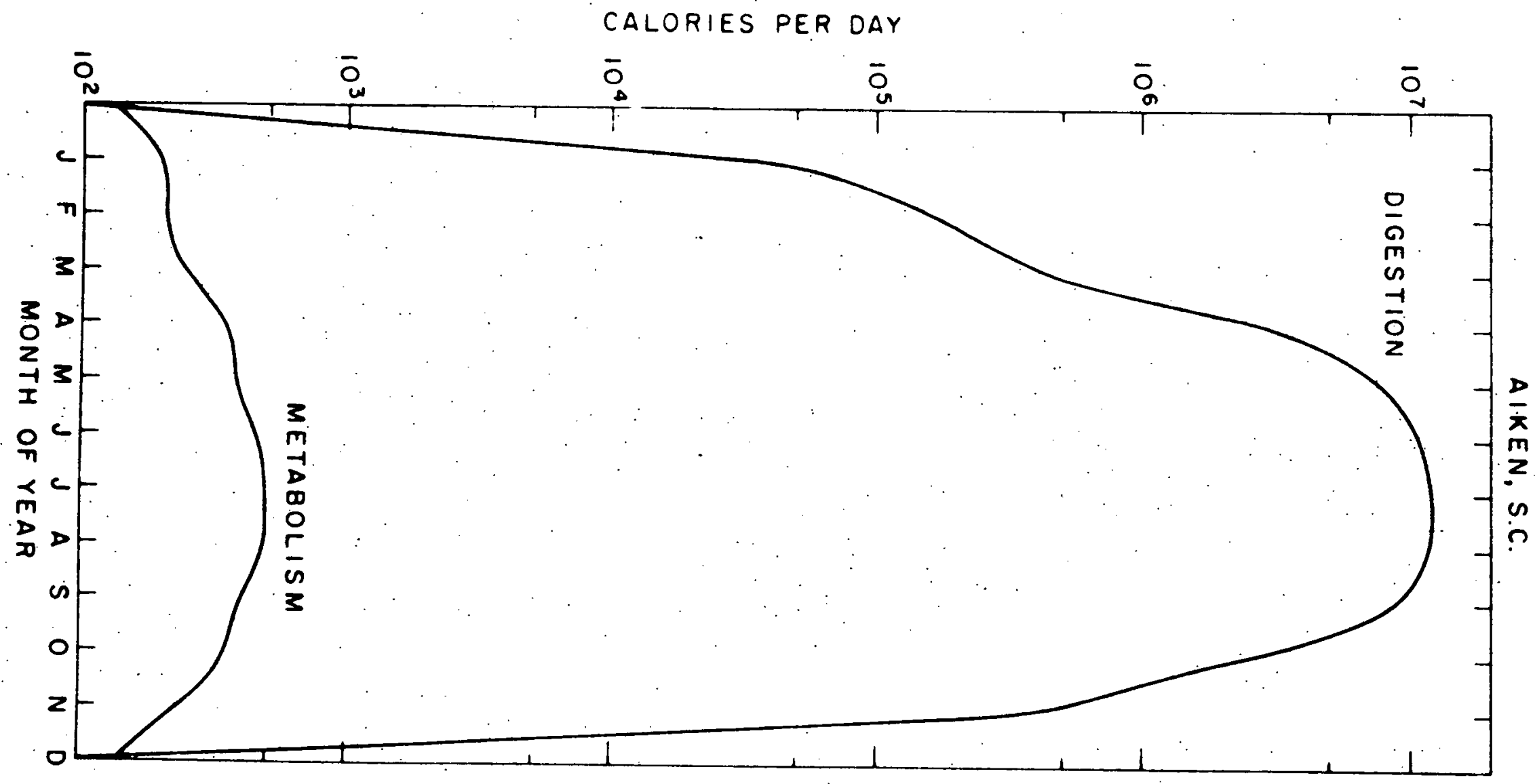

11

Fig. 13 Daily resting metabolism and potential daily maximum digestion using 10 year average days for Pellston, Michigan 
Table 1

$50 \mathrm{~g}$ Garter Snake Biomass Requirements for Northern and Southern United States

(Including $10^{\circ} \mathrm{C}$ Thermal Pollution)

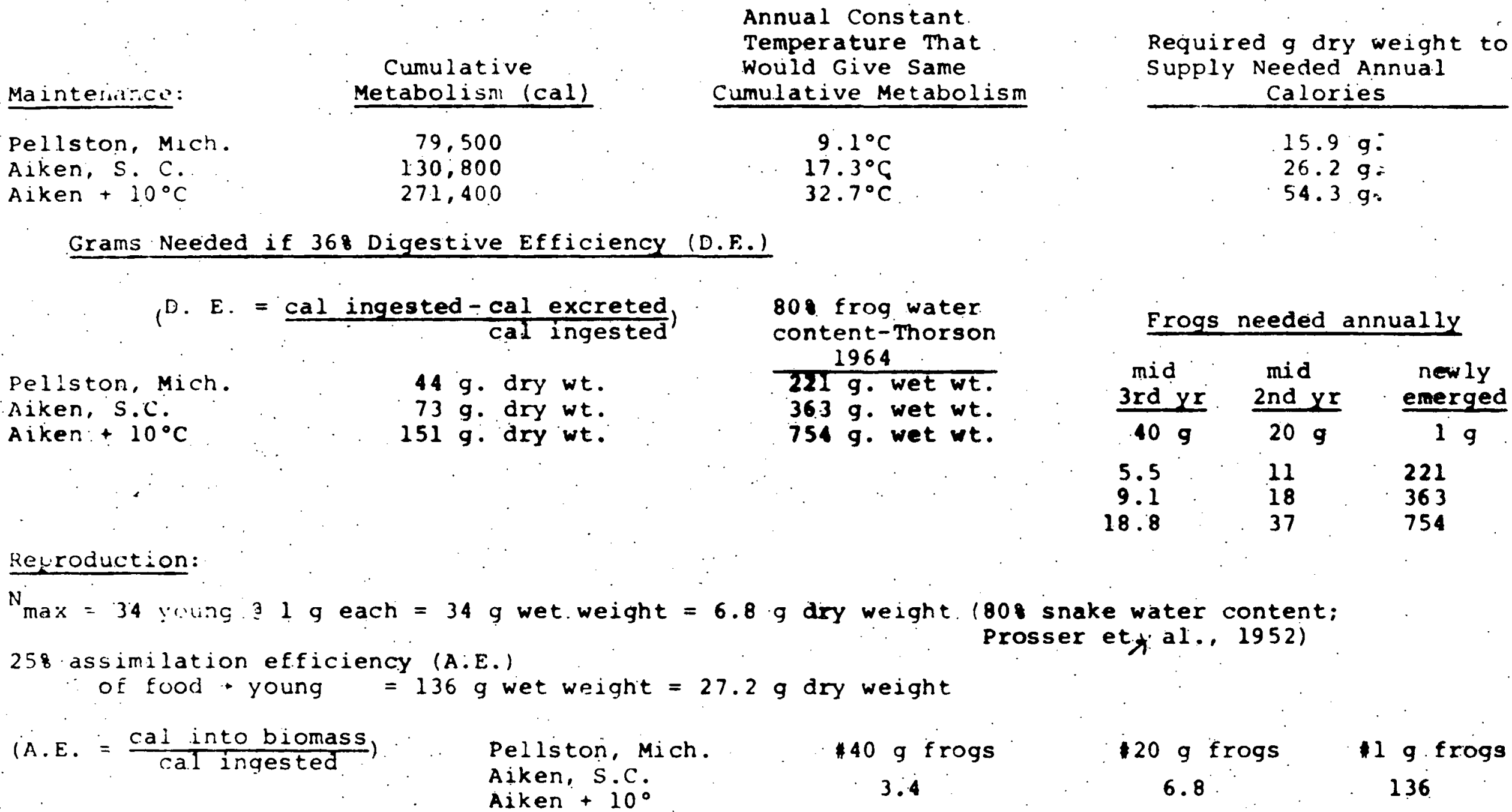

Growth: Snake mass: $50 \mathrm{~g} \rightarrow 100 \mathrm{~g}$ wet weight; $50 \mathrm{~g}$ wet weight to be added; $10 \mathrm{~g}$ dry weight to be added for 258 assimilation efficiency

$200 \mathrm{~g}$ vet weight needed;

$140 \mathrm{~g}$. frogs
$40 \mathrm{~g}$ dry weight needed

120 g frogs 1 g frogs 200 
Average Annual Available Activity Time

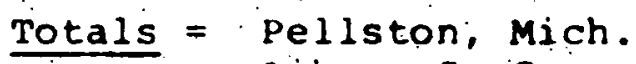

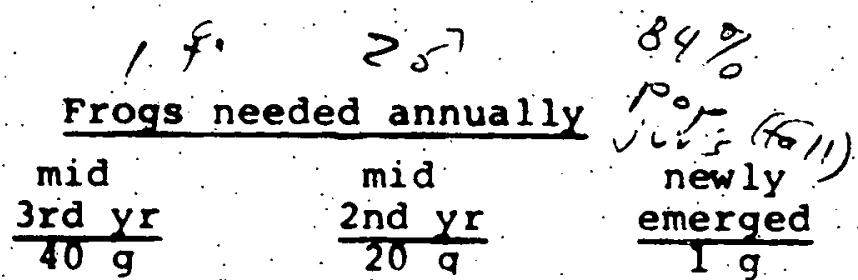

14

18

27
28

35

54

557

669

1090

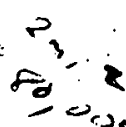

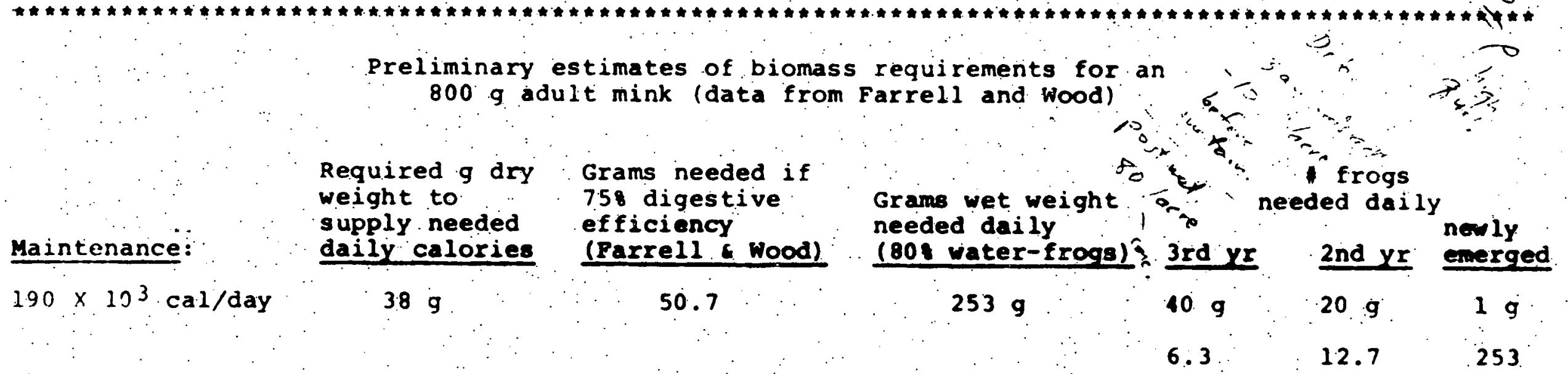

Note: This animal must consume the equivalent of 318 of its body weight/day. 


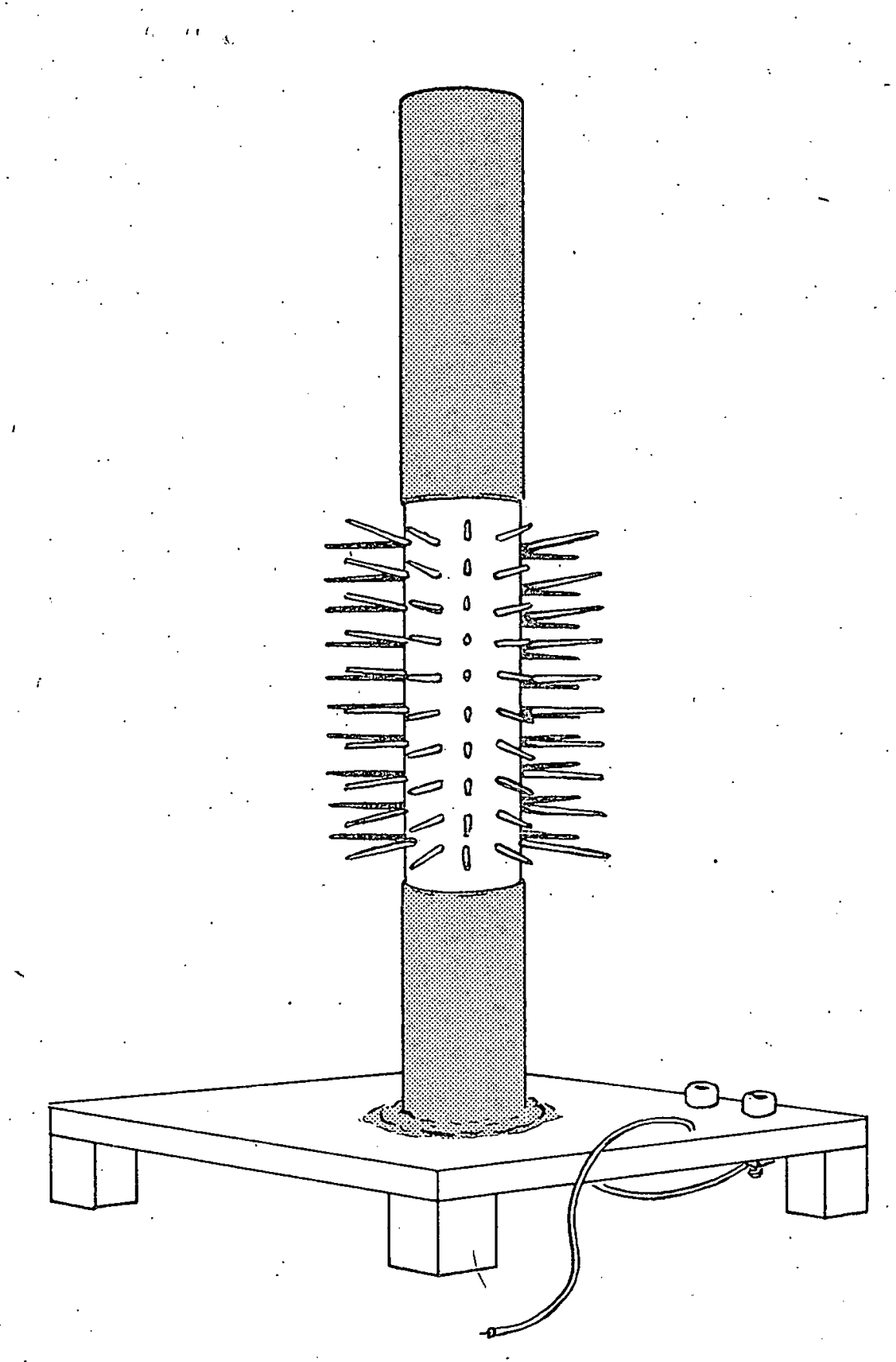

Figure 1 


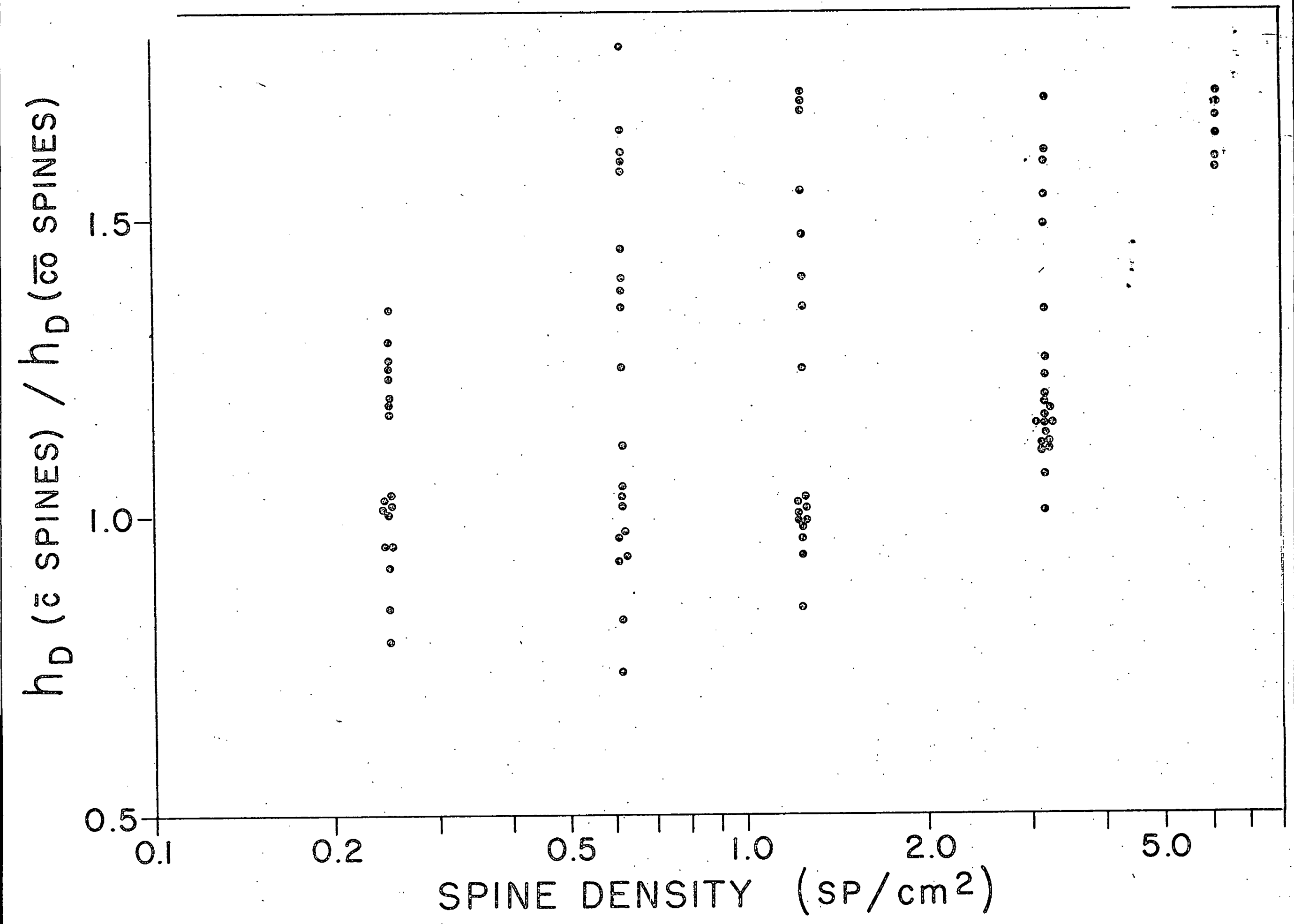

Figure 2 